\section{RMD Open}

Rheumatic \&

Musculoskeletal Diseases

\title{
All-cause mortality in systemic rheumatic diseases under treatment compared with the general population, 2015-2019
}

\author{
Vasiliki-Kalliopi Bournia (D) ," George E Fragoulis (D) , ${ }^{1}$ Panagiota Mitrou, ${ }^{2}$ \\ Konstantinos Mathioudakis, ${ }^{3}$ Anastasios Tsolakidis, ${ }^{3}$ George Konstantonis, ${ }^{1}$ \\ Georgia Vourli, ${ }^{4}$ Dimitrios Paraskevis, ${ }^{4}$ Maria G Tektonidou (D) , ${ }^{1}$ Petros P Sfikakis ${ }^{1}$
}

To cite: Bournia V-K, Fragoulis GE, Mitrou $P$, et al. All-cause mortality in systemic rheumatic diseases under treatment compared with the general population, 2015-2019. RMD Open 2021;7:e001694. doi:10.1136/ rmdopen-2021-001694

- Additional supplemental material is published online only. To view, please visit the journal online (http://dx.doi.org/10. 1136/rmdopen-2021-001694).

Received 8 April 2021 Accepted 3 October 2021

Check for updates

(C) Author(s) (or their employer(s)) 2021. Re-use permitted under CC BY-NC. No commercial re-use. See rights and permissions. Published by BMJ.

1Joint Rheumatology Program, National and Kapodistrian University of Athens Faculty of Medicine, Athens, Greece ${ }^{2}$ Hellenic Republic Ministry of Health, Athens, Greece ${ }^{3}$ IDIKA SA - e-Government Center for Social Security Services, Athens, Greece ${ }^{4}$ Department of Hygiene Epidemiology and Medical Statistics, National and Kapodistrian University of Athens Faculty of Medicine, Athens, Greece

Correspondence to Professor Petros P Sfikakis; psfikakis@med.uoa.gr

\section{ABSTRACT}

Objectives To compare current all-cause mortality rates in rheumatoid arthritis (RA), ankylosing spondylitis (AS), psoriatic arthritis (PsA), systemic lupus erythematosus (SLE) and systemic sclerosis (SSc) versus general population.

Methods In this population-based, retrospective cohort study, anonymised data on 11186586 citizens, including all patients with RA (42 735, 79\% female), AS (9707, 43\% female), PsA (13 779, 55\% female), SLE (10 440, 89\% female) and SSc (2277, 88\% female), (median age of 64/47/54/53/59 years at study entry, respectively), under prescribed treatment between 2015 and 2019, were extracted from the electronic database covering nearly $99 \%$ of the Greek population.

Results After 1:5 (patients:general population) matching for gender/age, we found that survival was worse in SSc, followed by SLE and inflammatory arthritis. Compared with the general population HRs for death increased from the first 3 years to 5 years of observation possibly due to increases in disease duration: RA (from 0.63 to 1.13 (95\% Cl: 1.05 to 1.22$), A S$ (from 0.62 to $1.01,(95 \% \mathrm{Cl}: 0.76$ to 1.33)), PsA (from 0.68 to $1.06,(95 \% \mathrm{Cl}: 0.88$ to 1.28$)$ ), SLE (from 1.52 to $1.98,(95 \% \mathrm{Cl}: 1.67$ to 2.33$)$ ) and SSc (from 2.27 to $4.24,(95 \% \mathrm{Cl}: 3.19$ to 5.63$)$ ). In both SLE and SSc mortality was increased in men than women and in patients younger than 50 years.

Conclusions Survival rates over 5 years in inflammatory arthritis under treatment are currently becoming comparable (AS/PSA) or slightly higher (RA) than those of the general population. However, all-cause mortality is almost twofold and fourfold higher in SLE and SSc, respectively, being even higher for male and younger patients.

\section{INTRODUCTION}

It is common knowledge that systemic rheumatic diseases are characterised by increased morbidity and mortality. ${ }^{12}$ In addition to disease-specific factors and iatrogenic damage (eg, drug-related side effects), this, could

\section{Key messages}

What is already known about this subject?

- Systemic rheumatic diseases are characterised by increased mortality compared with the general population, but recent studies, mostly in rheumatoid arthritis and less so in other diseases, have shown that the gap of excess mortality risk is steadily closing.

What does this study add?

- Using unbiased data on nearly 11 million people between 2015 and 2019, we show that current mortality risk among patients under treatment remains twofold higher for systemic lupus erythematosus and fourfold higher for systemic sclerosis, compared with the general population, being even higher for male and younger patients.

- In contrast, for the first time in a nationwide study, we show that mortality rates over 5 years in patients under treatment are almost comparable to the general population in rheumatoid arthritis, in ankylosing spondylitis and psoriatic arthritis.

How might this impact on clinical practice or further developments?

- Given that effective therapeutic options and treat-totarget strategies, including control of comorbidities, can explain the improved survival observed in rheumatoid arthritis and the spondylarthritides during the calendar years 2015-2019, similar approaches should be implemented in all systemic rheumatic diseases.

be associated with comorbid cardiovascular disease, malignancy and increased risk for infections. ${ }^{3-6}$ Mortality risk is largely different among various rheumatic diseases, ${ }^{3}{ }^{5-9}$ due to diverse underlying pathogenetic mechanisms and the degree of vital organ involvement, but also due to different therapeutic regimes used, and different age onset of each disease. However, change in mortality rates 
over time is dynamic, and certain aspects, in addition to variances in treatment, need to be considered. For example, different classification criteria used and/or the availability or introduction of novel diagnostic tests might affect the incidence of the index diseases. Moreover, over the last decades, clinics dedicated to a specific disease are becoming more common in many countries. This might associate with selection bias, reporting patients with more severe disease. ${ }^{7}$

Over the last years, the 'treat-to-target' approach gained ground in the field of rheumatic diseases and especially in inflammatory arthritis. ${ }^{1011}$ One could hypothesise that this strategy, along with the new therapeutic options introduced and the better control of comorbidities, may have led to decrease in the mortality rate of patients with systemic rheumatic diseases. In this setting, many studiesmost of them in rheumatoid arthritis (RA) - have shown that the gap of excess mortality risk, compared with general population, is steadily closing. ${ }^{12-15}$ Of note, the majority of these studies are based on data derived from large registries $5^{571415}$ and only few, reporting for systemic sclerosis (SSc) up to $2015^{8}$ and for systemic lupus erythematosus (SLE) up to $2013,{ }^{9}$ are population studies.

Since 2011 our country operates an electronic database for Social Security Services covering $99 \%$ of the Greek population and holding information regarding all prescriptions and their status (executed or not), all medical diagnoses according to the specific International Classification of Disease (ICD)-10, as well as all diagnostic procedures ordered by physicians either in relation with a specific condition or for presymptomatic testing. Given that both Greek citizens and legal immigrants living in Greece acquire free access to presymptomatic testing and vaccinations through the electronic database for Social Security Services, this database holds the records of nearly every person in the country, irrespective of health status. Furthermore, the database is linked via aspecific for each patient-number with the nationwide death records. Using this electronic database, we aimed to assess the mortality rates in RA, ankylosing spondylitis (AS), psoriatic arthritis (PsA), SLE and SSc patients under treatment in comparison with the general population free of these diseases between 2015 and 2019.

\section{PATIENTS AND METHODS}

In this nationwide, population based, retrospective, matched cohort study, we searched the electronic prescription database of the e-Government Center for Social Security Services (IDIKA), to capture all patients aged 18 years or older with RA, AS, PsA, SLE and SSc under prescribed disease-specific treatment in Greece, who filled at least one prescription for any drug listed below, between 1 January 2015 and 31 December 2019. We used predefined ICD-10 codes for RA, AS, PsA, SLE and SSc, in order to capture all patients who filled a prescription for any of the following drugs: conventional synthetic Disease Modifying Anti-Rheumatic Drugs [(cs) DMARDs] (sulfasalazine, methotrexate, azathioprine, leflunomide, ciclosporin, D-penicillamine, hydroxychloroquine, cyclophosphamide, mycophenolic acid), corticosteroids (betamethasone, dexamethasone, fluocortolone, methylprednisolone, paramethasone, prednisolone, prednisone, triamcinolone, hydrocortisone, cortisone, prednylidene, rimexolone, deflazacort, cloprednol, meprednisone, cortivazol), biological (b)DMARDs (abatacept, tocilizumab, anakinra, ustekinumab, secukinumab, rituximab, adalimumab, certolizumab pegol, etarnecept, golimumab, infliximab, belimumab), targeted synthetic (ts)DMARDs (tofacitinib, upadacitinib, baricitinib, apremilast), advanced vasodilatory therapy (bosentan, ambrisentan, sitaxentan, macitentan, riociguat, tadalafil, sildenafil, vardenafil, avanafil, udenafil, epoprostenol, iloprost, beraprost, treprostinil, selexipag) and antifibrotic therapy (nintedanib, pirfenidone) (see online supplemental tables 1 and 2 for an extensive list of ICD-10 and ATC5 codes, respectively). For the few patients (1.97 $\%$ ) who had filled consecutive prescriptions with more than one ICD-10 codes, we arbitrarily accepted the most recently used ICD-10 code to define diagnosis. The date when each patient filled the first prescription for one of the above-mentioned medications of interest, with one of

Table 1 Demographics at study entry of patients with RA, AS, PsA, SLE, SSc and age-matched and gender-matched individuals from the general population free of systemic rheumatic disease

\begin{tabular}{|c|c|c|c|c|c|c|c|c|c|c|}
\hline & \multicolumn{2}{|l|}{ RA } & \multicolumn{2}{|l|}{ AS } & \multicolumn{2}{|l|}{ PsA } & \multicolumn{2}{|l|}{ SLE } & \multicolumn{2}{|l|}{ SSc } \\
\hline & Patients & $\begin{array}{l}\text { General } \\
\text { population }\end{array}$ & Patients & $\begin{array}{l}\text { General } \\
\text { population }\end{array}$ & Patients & $\begin{array}{l}\text { General } \\
\text { population }\end{array}$ & Patients & $\begin{array}{l}\text { General } \\
\text { population }\end{array}$ & Patients & $\begin{array}{l}\text { General } \\
\text { population }\end{array}$ \\
\hline N & 42735 & 213675 & 9707 & 48535 & 13779 & 68895 & 10440 & 52200 & 2277 & 11385 \\
\hline $\begin{array}{l}\text { Female } \\
\text { gender } \\
\mathrm{N}(\%)\end{array}$ & 33641 (79) & 168205 (79) & $4163(43)$ & 20815 (43) & $7565(55)$ & 37825 (55) & 9315 (89) & 46575 (89) & 1998 (88) & $9990(88)$ \\
\hline $\begin{array}{l}\text { Median } \\
\text { (IQR) } \\
\text { age in } \\
\text { years }\end{array}$ & \multicolumn{2}{|c|}{$64(54-73)$} & \multicolumn{2}{|c|}{$47(38-56)$} & \multicolumn{2}{|c|}{$54(45-64)$} & \multicolumn{2}{|c|}{$53(42-64)$} & \multicolumn{2}{|c|}{$59(49-68)$} \\
\hline
\end{tabular}

AS, ankylosing Spondylitis; N, number; PsA, psoriatic arthritis; RA, rheumatoid arthritis; SLE, systemic lupus erythematosus; SSc, systemic sclerosis. 


\section{KAPLAN-MEIER SURVIVAL ESTIMATES}
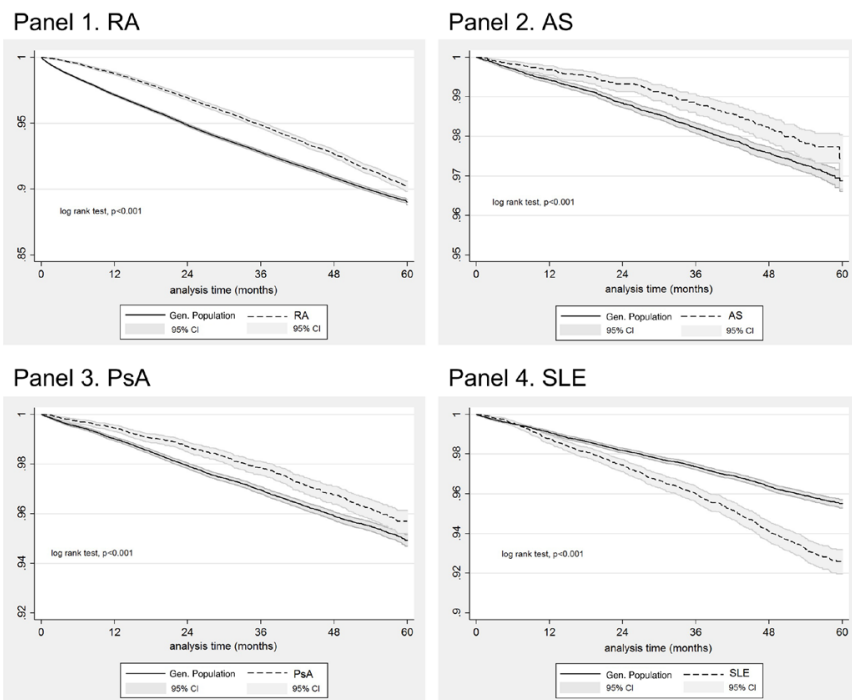

Panel 4. SLE

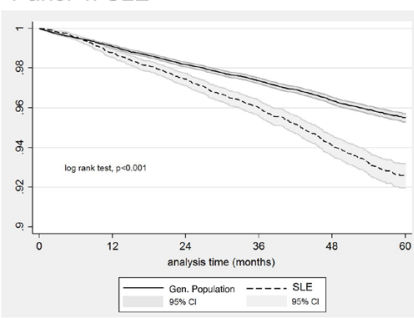

Panel 5. SSc

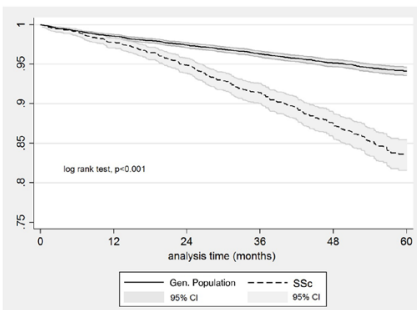

Figure 1 Kaplan-Meier survival curves for patients with rheumatoid arthritis (RA, $\mathrm{N}=42735$, panel 1), ankylosing spondylitis (AS, $\mathrm{N}=9707$, panel 2), psoriatic arthritis (PSA, $\mathrm{N}=13$ 779, panel 3), systemic lupus erythematosus (SLE, $\mathrm{N}=10$ 440, panel 4), systemic sclerosis (SSC, $\mathrm{N}=2277$, panel 5), and for age-matched and gender-matched individuals from the general population (1:5 exposed: unexposed ratio) included in our cohort between 1 January 2015 and 31 December 2019. Analysis time in months.

the diagnoses under study was defined as date of entry in the cohort.

For this 5-year period (2015-2019), the IDIKA database holds the prescription records of 11186586 citizens. To avoid selection bias, in our cohort, all patients with disease-specific prescribed medication were included,

Table 2 The average effect of systemic rheumatic diseases on risk of death from all causes during a 5-year follow-up time, between 1 January 2015 and 31 December 2019

\begin{tabular}{llll}
\hline Variable & HR & $95 \%$ Cl & P value \\
\hline RA & 0.74 & 0.71 to 0.77 & $<0.001$ \\
AS & 0.73 & 0.62 to 0.87 & $<0.001$ \\
PSA & 0.78 & 0.70 to 0.87 & $<0.001$ \\
SLE & 1.65 & 1.50 to 1.81 & $<0.001$ \\
SSc & 2.72 & 2.33 to 3.17 & $<0.001$ \\
\hline
\end{tabular}

Cox proportional HR analysis.

AS, ankylosing spondylitis; PsA, psoriatic arthritis; RA, rheumatoid arthritis; SLE, systemic lupus erythematosus; SSc, systemic sclerosis. based on ICD-10 codes. Patients buying their rheumatology drugs over the counter are not captured, however, the percentage of patients acquiring their medication without prescription for five consecutive years should be too low to have significantly affected our results. Patients were randomly matched for gender and year of birth (individual matching 1:5) to individuals from the general population free of RA, AS, PsA, SLE and SSc, who had a valid social security number during the same period of time. For all subjects free of systemic rheumatic disease the date of entry in the cohort was selected to match that of their index patient. Here forth, all exposed subjects in our cohort will be referred to as patients and all unexposed subjects will be referred to as general population. For all study participants, we were able to record the date of birth, gender, as well as vital status and date of death between 1 January 2015 and 31 December 2019. Our study did not extend beyond 31 December 2019 to avoid recording any possible effects of the COVID-19 pandemic on the survival of patients with rheumatic diseases.

The primary outcome of the study was the assessment of all-cause mortality in patients with RA, AS, PsA, SSc and SLE compared with the general population.

\section{Statistics}

Survival time was estimated from the time of entry in the cohort until the event of interest (death from all causes), or until administrative censoring if the event was not observed. Threeyear and 5-year survival of patients with RA, AS, PsA, SLE and SSc and their age and gender matched counterparts derived from the general population was estimated by Kaplan-Meier analysis, while differences were assessed by the Log Rank test. Graphs are presented using a time scale in years (12 monthintervals). Cox regression model was used to evaluate the effect of each systemic rheumatic disease on death from all causes. The proportional hazards assumption was tested using Schoenfeld residuals and graphically assessed using $-\log (\log (\mathrm{S}(\mathrm{t}))$ graph. To account for the violations of the proportional hazards assumption, an interaction of each disease with time was allowed. For this purpose, a cut-off of 36 months was used. Therefore, HRs are presented separately for the time period prior to and following 36 months. A subgroup analysis was performed based on patient gender and age, using 50 years at cohort entry as a cut-off. This cut-off was selected as it represents the median age of the adult population included in the prescription database. There were no missing data on covariates we selected to record. Multivariable analysis was not possible due to lack of data on disease duration, disease severity, socioeconomic status, comorbidities, smocking status. Statistical analysis was performed using the Stata statistical software package (StataCorp. 2013. Stata Statistical Software: Release V.13, StataCorp.) 
Table $3 \mathrm{HR}$, with $95 \% \mathrm{Cl}$ and $p$ values, for the effect of RA, AS, PsA, SLE and SSc on all-cause mortality of the entire patient cohort for the first 3 years ( $0-36$ months) and for the following 2 years ( $>36$ months) of follow-up

\begin{tabular}{|c|c|c|c|c|c|c|}
\hline \multirow[b]{3}{*}{ Variable } & \multicolumn{3}{|c|}{ Entire cohort, 0-36 months of follow-up } & \multicolumn{3}{|c|}{ Entire cohort, >36 months of follow-up } \\
\hline & \multicolumn{3}{|c|}{ HR (main effect) } & \multicolumn{3}{|c|}{ HR (main effect) } \\
\hline & & $95 \% \mathrm{Cl}$ & $P$ value & & $95 \% \mathrm{CI}$ & $P$ value \\
\hline RA & 0.63 & 0.60 to 0.66 & $<0.001$ & $1.13^{*}$ & 1.05 to 1.22 & 0.002 \\
\hline AS & 0.62 & 0.50 to 0.77 & $<0.001$ & $1.01^{* *}$ & 0.76 to 1.33 & 0.958 \\
\hline PsA & 0.68 & 0.59 to 0.78 & $<0.001$ & $1.06^{\star}$ & 0.88 to 1.28 & 0.537 \\
\hline SLE & 1.52 & 1.35 to 1.70 & $<0.001$ & $1.98^{\star \star}$ & 1.67 to 2.33 & $<0.001$ \\
\hline SSc & 2.27 & 1.89 to 2.74 & $<0.001$ & $4.24^{*}$ & 3.19 to 5.63 & $<0.001$ \\
\hline
\end{tabular}

$P$ value for interaction ${ }^{*}<0.001 ;{ }^{* *}<0.05$.

AS, ankylosing spondylitis; PsA, psoriatic arthritis; RA, rheumatoid arthritis; SLE, systemic lupus erythematosus; SSc, systemic sclerosis.

\section{RESULTS}

Patient demographics

As shown in table 1 our search of the database revealed 42735 patients with RA ( $79 \%$ female), 9707 patients with AS (43\% female), 13779 patients with PsA (55\% female), 10440 patients with SLE (89\% female) and 2277 patients with SSc ( $88 \%$ female). These were randomly matched to 394690 subjects from the general population of the same age and gender, using a 1:5 ratio. Patients with RA were older compared with other patient groups, with a median (IQR) age of 64 (54-73) years, followed by patients with SSc, PsA, SLE and AS, with a median (IQR) age of 59 (49-68), 54 (45-64), 53 (42-64) and 47 (38-56) years, respectively. Total follow-up was 268222 person-years for patients with systemic rheumatic disease (142 883 for patients with RA, 32840 for patients with AS, 45747 for patients with PsA, 39008 for patients with SLE and 7744 for patients with SSc) and 1327687 person-years for matched individuals from the general population (700 234 for subjects matched to patients with RA, 163 420 for subjects matched to patients with AS, 227006 for subjects matched to patients with PsA, 197021 for subjects matched to patients with SLE and 40007 for subjects matched to patients with SSc), respectively.

\section{Survival analysis in the entire population}

During the study period, there were 582551 deaths documented in the database, of which 2725 among RA (death rate $(95 \% \mathrm{CI}): 19.07$ (18.37 to 19.80$)$ per 1000 RA patientyears) 150 among AS (death rate (95\% CI): 4.57 (3.89 to 5.36) per 1000 AS patient-years) 376 among PsA (death rate $(95 \% \mathrm{CI}): 8.22$ (7.43 to 9.09$)$ per 1000 PsA patientyears), 585 among SLE (death rate (95\% CI): 15.00 (13.83 to 16.26$)$ per 1000 SLE patient-years) and 261 among SSc patients (death rate (95\% CI): 33.70 (29.85 to 38.05$)$ per 1000 SSc patient-years); there were 22464 deaths among matched subjects from the general population (online supplemental table 3$)$. The respective death rates (95\% CI) for the general population were 24.16 (23.80 to 24.53) per 1000 person-years for subjects matched to RA, 6.12 (5.75 to 6.51) per 1000 person-years for subjects matched to AS, 10.33 (9.92 to 10.75 ) per 1000 person-years for subjects matched to PsA, 9.20 (8.78 to 9.63) per 1000 person-years for subjects matched to SLE, and 12.45 (11.40 to 13.59) per 1000 person-years for subjects matched to SSc. KaplanMeier survival curves for RA, AS, PsA, SSc, SLE patients and for age and gender matched subjects from the general population, entered in our study between 1 January 2015 and 31 December 2019 are shown in figure 1. Three-year and 5-year survival rates are presented in online supplemental table 4. As shown from the plots patients with SSc have the worse survival, followed by patients with SLE and patients with inflammatory arthritis.

Assuming proportionality of HRs over time, we performed Cox regression analysis comparing the risk of death between each group of systemic rheumatic disease patients and age-matched and gender-matched individuals derived from the general population, free of systemic rheumatic disease. The average effect of underlying systemic rheumatic disease on patient survival is shown in table 2, which indicates that the average risk of death from all causes over the 5-year follow-up period was lower for RA (HR: 0.74, (95\% CI: 0.71 to 0.77$)$ ), AS (HR:0.73, (95\% CI: 0.62 to 0.87$)$ ) and PsA (HR: 0.78 , (95\% CI: 0.70 to 0.87$))$ patients compared with the general population, whereas for SLE (HR: 1.65, (95\% CI: 1.50 to 1.81$)$ ) and SSc (HR: 2.72, (95\% CI: 2.33 to 3.17$)$ ) patients it was higher.

After testing for proportionality, we found that the risk of death from all causes changed over time, therefore, an interaction with time was allowed. As shown in table 3, the HR for the effect of RA during the first 3 years of follow-up was 0.63 (95\% CI: 0.60 to 0.66 ), increasing to 1.13 (95\% CI: 1.05 to 1.22 ) in the next 2 years, due to the interaction effect. Likewise, the HR for the effect of AS and PsA on death from all causes was $0.62(95 \%$ CI: 0.50 to 0.77 ) and 0.68 (95\% CI: 0.59 to 0.78$)$, for the first 3 years, respectively, becoming comparable to that of the general population in the following 2 years (1.01 (95\% CI: 0.76 to 1.33 ) and 1.06 (95\% CI: 0.88 to 1.28 ), for AS and PsA, respectively). On the other hand, the HR for the effect of SLE and SSc was 1.52 (95\% CI: 1.35 to 1.70) and 2.27 (95\% CI: 1.89 to 2.74$)$ for the first 3 years, respectively, rising to 1.98 (95\% CI: 1.67 to 2.33 ) and 4.24 (95\% CI: 3.19 to 5.63 ) in the next 2 years, respectively. 
A Males

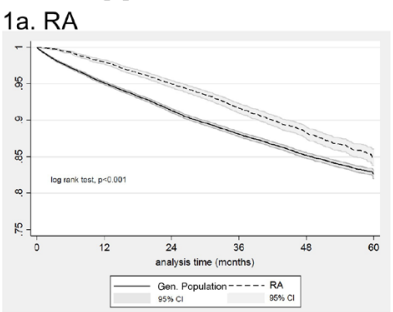

2a. AS

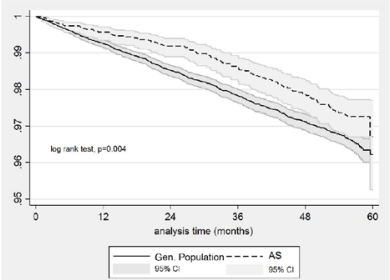

3a. PsA

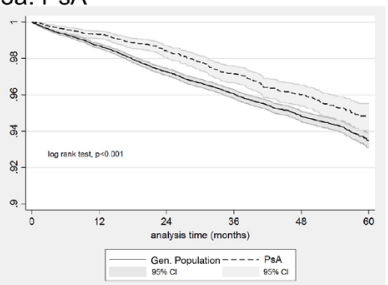

4a. SLE

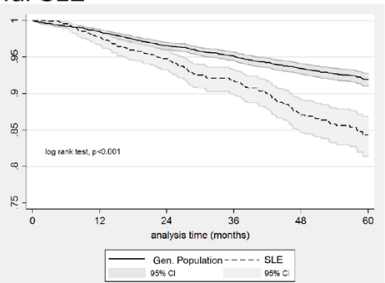

5a. SSc

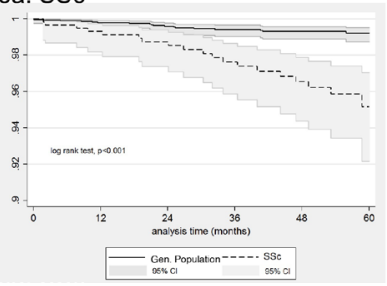

B Females

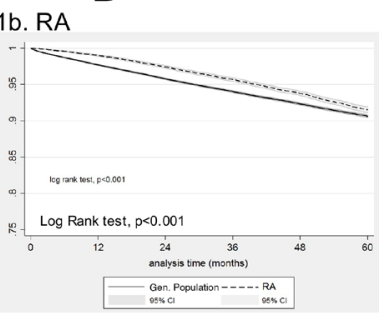

2b. AS

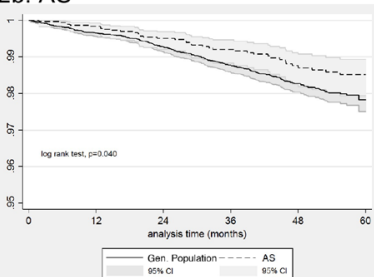

3b. PsA

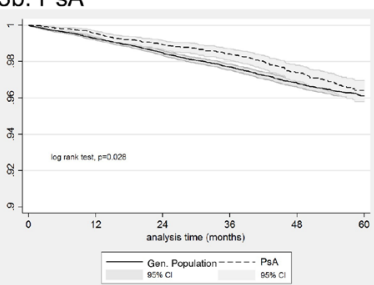

4b. SLE

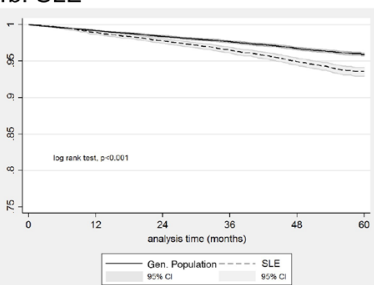

5 b. SSc

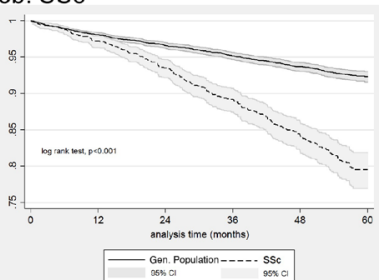

Figure 2 Kaplan-Meier survival curves for female $(A)$ and male $(B)$ patients with (1) rheumatoid arthritis (RA, $N=33$ 641 females, $\mathrm{N}=9094$ males), (2) ankylosing spondylitis (AS, $\mathrm{N}=4163$ females, $\mathrm{N}=5544$ males), (3) psoriatic arthritis (PSA, $\mathrm{N}=7565$ females, $\mathrm{N}=6214$ males), (4) systemic lupus erythematosus (SLE, $\mathrm{N}=9315$ females, $\mathrm{N}=1125$ males), (5) systemic sclerosis (SSC, $\mathrm{N}=1,998$ females, $\mathrm{N}=279$ males) and for age-matched and gender-matched individuals from the general population (1:5 exposed:unexposed ratio) included in our cohort between 1 January 2015 and 31 December 2019. Analysis time in months.

Higher risk of death in male versus female patients with SLE and SSc

To investigate the effect of gender on all-cause mortality of patients with systemic rheumatic diseases we performed a subgroup analysis in male and female patient subsets. Figure 2 shows Kaplan-Meier survival analysis in male and female study participants. As seen from the curves, male

SLE and SSc patients fare considerably worse compared with their female counterparts.

When Cox regression models were used, the assumption of proportionality of hazards was maintained for female patients with AS and for male patients with SLE, but was violated for all other patient subgroups, necessitating the introduction of an interaction term with time in the respective analysis. Our results (table 4) indicated that the effect of SLE was slightly more pronounced among male patients compared with females for the first 3 years of follow-up. In fact, the HR for the effect of SLE on death from all causes during the first 3 years was 1.91 (95\% CI: 1.56 to 2.35) among male patients, compared with 1.47 (95\% CI: 1.29 to 1.67) among female patients. A marginal difference between male and female patients could also be seen for the effect of SSc on all-cause mortality after the first 3 years of follow-up. More specifically, the HR for the effect of SSc on all-cause mortality was similar for males (2.56 (95\% CI: 1.57 to 4.16)) and females (2.23 (95\% CI: 1.83 to 2.72)) up to the first 3 years, increasing to 7.28 (95\% CI: 3.30 to 16.06 ) and 3.90 (95\% CI: 2.87 to 5.29) for males and females, respectively, thereafter. Differences between genders in other rheumatic diseases were not so pronounced.

\section{Highest risk of death in patients with SLE and SSc younger than $\mathbf{5 0}$ years}

In a second subgroup analysis, we assessed the risk of death from all causes in the group of study participants aged under 50 years and in those aged 50 years or older at cohort entry. Kaplan-Meier survival curves are shown in figure 3. As expected, older patients had worse survival across all systemic rheumatic diseases, which was more pronounced in SLE and SSc. In Cox regression analysis, violation of the proportionality assumption was found for both subgroups of patients with RA and for the subgroups of AS, SpA, SLE and SSc patients aged 50 years and older, in which cases an interaction term was added in the model. Our findings (table 5) clearly indicate that the effect of SLE on all-cause mortality was more pronounced among younger patients, an observation which was also true for younger patients with SSc during the first 3 years of follow-up. More specifically, the HR for death from all causes for patients with SLE and SSc $<50$ years was 2.74 (95\% CI: 1.92 to 3.92 ) and 5.18 (95\% CI: 2.71 to 9.89), respectively. In comparison, the initial HR for the effect of SLE and SSc on the survival of patients $\geq 50$ years of age was 1.47 (95\% CI: 1.30 to 1.66$)$ and 2.20 (95\% CI: 1.82 to 2.66), respectively, during the first 3 years of follow-up, but further increased to 1.89 (95\% CI: 1.59 to 2.25$)$ and 4.01 (95\% CI: 3.00 to 5.37$)$ respectively, during the subsequent 2 years of follow-up, due to interaction with time.

In contrast, the HR for the effect of the inflammatory arthritides on all-cause mortality seemed to favour the younger patient population, at least for the last 2 years of follow-up. More specifically, after the third year of follow-up, the HR for the effect of RA on death from all causes was 1.12 (95\% CI: 1.04 to 1.21) in the older patient 
Table $4 \mathrm{HR}$, with $95 \% \mathrm{Cl}$ and $\mathrm{p}$ values, for the effect of RA, AS, PSA, SLE and SSc on all-cause mortality of male and female patients for the first 3 years (0-36 months) and for the following 2 years (>36 months) of follow-up

\begin{tabular}{|c|c|c|c|c|c|c|c|}
\hline \multirow{3}{*}{$\begin{array}{l}\text { Systemic } \\
\text { rheumatic } \\
\text { disease }\end{array}$} & \multirow[b]{3}{*}{ Gender } & \multicolumn{3}{|c|}{ 0-36 months of follow-up } & \multicolumn{3}{|c|}{$>36$ months of follow-up } \\
\hline & & \multicolumn{3}{|c|}{ HR (main effect) } & \multicolumn{3}{|c|}{ HR (main effect) } \\
\hline & & & $95 \% \mathrm{Cl}$ & P value & & $95 \% \mathrm{Cl}$ & $P$ value \\
\hline \multirow[t]{2}{*}{ RA } & Male & 0.6 & 0.55 to 0.65 & $<0.001$ & $1.13^{\star}$ & 0.98 to 1.30 & 0.094 \\
\hline & Female & 0.65 & 0.61 to 0.69 & $<0.001$ & $1.13^{\star}$ & 1.03 to 1.23 & 0.008 \\
\hline \multirow[t]{2}{*}{ AS } & Male & 0.61 & 0.47 to 0.80 & $<0.001$ & $1.06^{\star \star}$ & 0.77 to 1.46 & 0.715 \\
\hline & Female & 0.7 & 0.50 to 0.98 & 0.042 & 0.7 & 0.50 to 0.98 & 0.042 \\
\hline \multirow[t]{2}{*}{ PsA } & Male & 0.68 & 0.57 to 0.81 & $<0.001$ & $0.94^{\star *}$ & 0.72 to 1.22 & 0.63 \\
\hline & Female & 0.69 & 0.55 to 0.84 & $<0.001$ & $1.22^{*}$ & 0.93 to 1.60 & 0.147 \\
\hline \multirow[t]{2}{*}{ SLE } & Male & 1.91 & 1.56 to 2.35 & $<0.001$ & 1.91 & 1.56 to 2.35 & $<0.001$ \\
\hline & Female & 1.47 & 1.29 to 1.67 & $<0.001$ & $1.87^{\star \star}$ & 1.55 to 2.26 & $<0.001$ \\
\hline \multirow[t]{2}{*}{ SSc } & Male & 2.56 & 1.57 to 4.16 & $<0.001$ & $7.28^{\star \star}$ & 3.30 to 16.06 & $<0.001$ \\
\hline & Female & 2.23 & 1.83 to 2.72 & $<0.001$ & $3.90^{\star *}$ & 2.87 to 5.29 & $<0.001$ \\
\hline
\end{tabular}

$P$ value for interaction ${ }^{*}<0.001 ;{ }^{* *}<0.05$.

AS, Ankylosing Spondylitis; PsA, psoriatic arthritis; RA, rheumatoid arthritis; SLE, systemic lupus erythematosus; SSc, systemic sclerosis.

subgroup, whereas it was non-significant in the younger patient subgroup. Likewise, during the last 2 years of follow-up, the HR for the effect of AS and PsA on death from all causes was 0.57 (95\% CI: 0.33 to 0.96 ) and 0.52 (95\% CI: 0.28 to 0.95 ) among younger patients, but it was non-significant among older patients. A less pronounced effect of disease on all-cause mortality among younger individuals was also seen for PsA during the first 3 years of follow-up (HR: 0.52 (95\% CI: 0.28 to 0.95 ) for the younger group vs 0.69 (95\% CI: 0.60 to 0.79 ) in the older group).

\section{DISCUSSION}

Herein, using data on more than 11 million people during 2015-2019, we show that current mortality risk is much higher for SLE and SSc and especially for male and younger patients, compared with the general population. In contrast, we show that mortality rates in patients under treatment for inflammatory arthritis are slightly higher (for RA) or comparable (for AS and PsA) to the general population. This possibly reflects that newer strategies (eg, treat-to-target) are more effective in the control of inflammation, also affecting mortality.

As regards to SLE, in the largest study so far examining all US residents, however, based only on death certificates from the national mortality database and census data, it was found that SLE mortality decreased over the last 50 years (1968-2013) but still remained higher compared with the general population. In fact, an inverted U-shape distribution was observed for SLE mortality in this study, resulting in sustained decrease over the last decades. ${ }^{9}$ Another study, following-up about 1700 patients with SLE in Toronto lupus clinic between 1971 and 2013, showed that mortality rate was dramatically decreased over the last years, remaining higher though compared with the general population; in accordance with our findings, mortality risk was much higher in younger people (age $<40$ years old). ${ }^{6}$ As regards to $\mathrm{SSc}$, data are even more limited. In the largest cohort study so far, mortality rates increased during 1968-2000, but decreased each year thereafter till $2015,{ }^{8}$ while in a recent meta-analysis, standardised mortality ratio (SMR) in SSc was found about 3.5. ${ }^{1617}$ In a relatively large cohort of SSc patients, it was shown that mortality is more pronounced in patients with early disease. ${ }^{18}$

As regards to inflammatory arthritis, in previous decades, it was clear that patients with RA had higher mortality compared with the general population. Despite some disagreements, ${ }^{19}$ it seems that this gap is gradually closing. ${ }^{12} 1520$ A large study from the UK, examining data obtained between 1994 and 2010, compared patients with RA to the general population and showed an increased mortality. ${ }^{5}$ In another study examining mortality rates in Canada, investigators showed that mortality in RA decreased over time, but remained higher compared with the general population. ${ }^{21}$ Contrary, other studies have shown that over the last years there is an improving trend in RA mortality. In fact, it has been suggested that all-cause mortality is improved to a greater degree in patients with RA compared with the general population. ${ }^{15}$ Provan et al showed that all-cause and CVD mortality was increased for patients with RA up to 2004 but not after this date. ${ }^{22}$ Similarly, another group showed that mortality was increased for RA, in patients diagnosed from 1996 to 2000 , but not after that time point. ${ }^{13}$ The more recent large study using data from a Danish registry showed that all-cause mortality was similar between RA and general population, ${ }^{14}$ despite the fact that cardiac deaths and major adverse cardiovascular events were more common in the former.

Several characteristics could affect mortality rates in RA. In general, mortality seems to be increased in established 
A Age $<50$ years

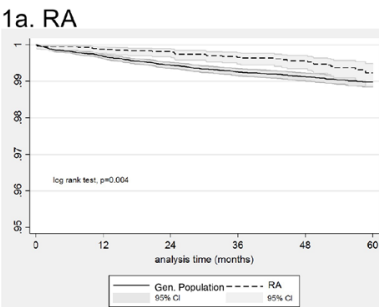

2a. AS
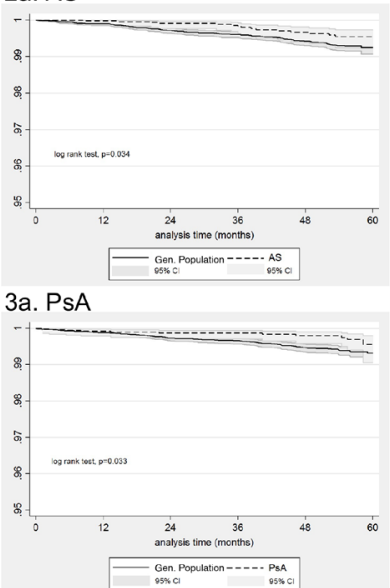

4a. SLE

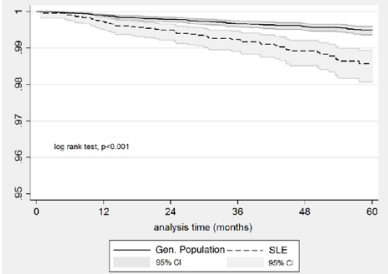

5a. SSc

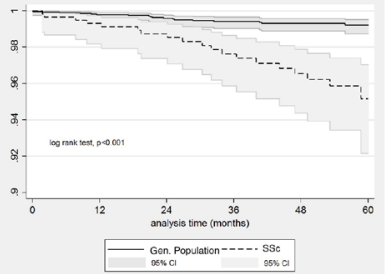

\section{B Age $\geq \mathbf{5 0}$ years}

1b. RA

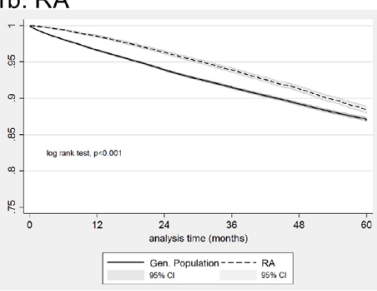

2b. AS

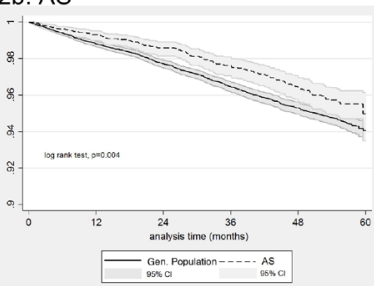

3b. PsA

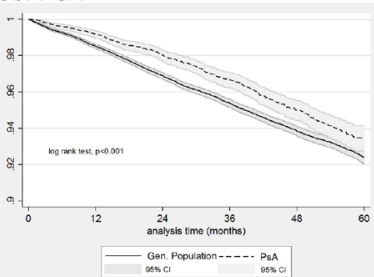

4b. SLE

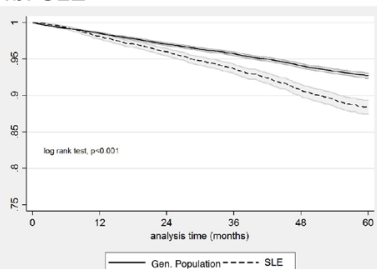

5b. SSc

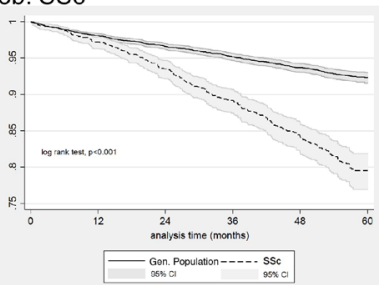

Figure 3 Kaplan-Meier survival curves for patients $<50$ years (A) and $\geq 50$ years of age $B$ ) with (1) rheumatoid arthritis (RA, N=7099 $<50$ years, $N=35636 \geq 50$ years), (2) ankylosing spondylitis (AS, $N=5466<50$ years, $N=4241 \geq 50$ years), (3) psoriatic arthritis (PSA, $\mathrm{N}=5048<50$ years, $\mathrm{N}=8731$ $\geq 50 y e a r s$ ), (4) systemic lupus erythematosus (SLE, $N=4373$ $<50$ years, $\mathrm{N}=6067 \geq 50$ years), (5) systemic sclerosis (SSC, $\mathrm{N}=600<50$ years, $\mathrm{N}=1677 \geq 50$ years) and for age-matched and gender-matched individuals from the general population (1:5 exposed:unexposed ratio) included in our cohort between 1 January 2015 and 31 December 2019. Analysis time in months.

compared with early RA, possibly due to accumulated comorbidities and chronic inflammation. ${ }^{21} \mathrm{~A}$ recent study of patients with early RA but a long follow-up (ie, 23 years), enrolling low number of patients though, showed that mortality in RA was comparable to the general population. ${ }^{23}$ Seeing the other flip of the coin, disease duration might negatively affect the observed mortality.
In an inception RA cohort, with a long follow-up, differences between observed and expected mortality emerged after 10 years of follow-up. ${ }^{24}$ Along the same lines, in data obtained from a Swedish registry for early RA, it was found that excess mortality for individuals with RA compared with comparators from general population appeared 5 years after disease diagnosis. ${ }^{25}$ Finally, data from WHO have shown that although RA excess mortality is declining over time, there are significant disparities between countries. ${ }^{26}$

As regards to spondylarthritis (SpA), the classification criteria introduced in the last decade have made comparisons between the few relevant studies conducted at different time points difficult. This is due to the fact that many different subcategories of diseases, like PsA or AS are classified under the SpA umbrella. Data for AS are indeed limited. However, there is evidence that mortality has improved over the last years. ${ }^{27}$ Herein, we clearly show that death risk for patients with AS under treatment is decreased compared with the general population. Importantly, $88 \%$ of our patients with AS were on treatment with biologics, thus on a better control of their disease. On the other hand, we were not able to examine whether there is some risk for specific causes of death, like infections, as has been shown by others. ${ }^{27} 28$ As regard to PsA, one study of about 8500 patients incorporating data obtained between 1994 and 2010, showed that irrespective of treatment received, patients with PsA did not display higher mortality compared with the general population ${ }^{5}$ or increased rates of cause-specific death. $^{7}$ In contrast, another population-based study enrolling $40 \%$ of the total population of Canada, found that SMR for psoriasis and PsA decreased over the last twenty years (1996-2016) but was still higher compared with the general population. ${ }^{3}$ Also, age-specific SMR had an inverted U-shape distribution with mortality being higher in individuals aged between 50 and 59 years old. In contrast, herein we show that mortality risk in patients with PsA is lower than the general population for the first 3 years after disease diagnosis, becoming comparable to the general population thereafter. Plausible explanations for this disagreement are that our study used different entry criteria and also examines data between 2015 and 2019, during which time two-thirds of patients are being treated with biologics. Other smaller-scale studies clearly show that mortality in PsA is improving over calendar years. 2930

Our study has specific strengths and limitations. The major strength is that the entire population of one country is included, avoiding thus selection bias. We also examine simultaneously five systemic rheumatic diseases within the same population, whereas mortality was recorded for 5 years (2015-2019). We opted to use the years 2015-2019, having in mind that COVID-19 pandemic might have affected the mortality in patients with systemic rheumatic diseases. Notably, a recent study has shown that the relative mortality risk for RA and other inflammatory arthritides in 2020, compared with general 
Table $5 \mathrm{HR}$, with $95 \% \mathrm{Cl}$ and $\mathrm{p}$ values, for the effect of RA, AS, PSA, SLE and SSc on all-cause mortality of patients $<50$ years and $\geq 50$ years of age for the first 3 years ( $0-36$ months) and for the following 2 years ( $>36$ months) of follow-up

\begin{tabular}{|c|c|c|c|c|c|c|c|}
\hline \multirow{3}{*}{$\begin{array}{l}\text { Systemic } \\
\text { rheumatic } \\
\text { disease }\end{array}$} & \multirow[b]{3}{*}{ Age (years) } & \multicolumn{3}{|c|}{ 0-36 months of follow-up } & \multicolumn{3}{|c|}{$>36$ months of follow-up } \\
\hline & & \multicolumn{3}{|c|}{ HR (main effect) } & \multicolumn{3}{|c|}{ HR (main effect) } \\
\hline & & & $95 \% \mathrm{Cl}$ & $P$ value & & $95 \% \mathrm{Cl}$ & $P$ value \\
\hline \multirow[t]{2}{*}{ RA } & $<50$ & 0.43 & 0.28 to 0.69 & $<0.001$ & $1.36^{\star \star}$ & 0.72 to 2.59 & 0.345 \\
\hline & $\geq 50$ & 0.63 & 0.60 to 0.67 & $<0.001$ & $1.12^{*}$ & 1.04 to 1.21 & 0.002 \\
\hline \multirow[t]{2}{*}{ AS } & $<50$ & 0.57 & 0.33 to 0.96 & 0.037 & 0.57 & 0.33 to 0.96 & 0.037 \\
\hline & $\geq 50$ & 0.65 & 0.52 to 0.83 & $<0.001$ & $1.04^{\star \star}$ & 0.77 to 1.41 & 0.806 \\
\hline \multirow[t]{2}{*}{ PsA } & $<50$ & 0.52 & 0.28 to 0.95 & 0.036 & 0.52 & 0.28 to 0.95 & 0.036 \\
\hline & $\geq 50$ & 0.69 & 0.60 to 0.79 & $<0.001$ & $1.08^{*}$ & 0.89 to 1.31 & 0.418 \\
\hline \multirow[t]{2}{*}{ SLE } & $<50$ & 2.74 & 1.92 to 3.92 & $<0.001$ & 2.74 & 1.92 to 3.92 & $<0.001$ \\
\hline & $\geq 50$ & 1.47 & 1.30 to 1.66 & $<0.001$ & $1.89^{*}$ & 1.59 to 2.25 & $<0.001$ \\
\hline \multirow[t]{2}{*}{ SSc } & $<50$ & 5.18 & 2.71 to 9.89 & $<0.001$ & 5.18 & 2.71 to 9.89 & $<0.001$ \\
\hline & $\geq 50$ & 2.2 & 1.82 to 2.66 & $<0.001$ & $4.01^{* *}$ & 3.00 to 5.37 & $<0.001$ \\
\hline
\end{tabular}

$P$ value for interaction ${ }^{*}<0.001 ;{ }^{* *}<0.05$.

AS, ankylosing spondylitis; PsA, psoriatic arthritis; RA, rheumatoid arthritis; SLE, systemic lupus erythematosus; SSc, systemic sclerosis.

population remained unchanged. ${ }^{31}$ On the other hand, we were not able to capture patients who did not have a prescription for their rheumatology drugs, but instead purchased their drugs over the counter; our unpublished data suggest that these individuals are few. In addition, misclassification can always be an issue in studies based on large prescription databases. To minimise this effect in our study we only selected patients under treatment with corticosteroids and/or DMARDs who had filled in their prescriptions. Also, we were not able to control for other confounders such as disease duration and severity, socioeconomic status, comorbidities, smoking or to perform analyses for cause-specific mortality. One should also be cautious in interpreting $p$ values of Log-Rank tests in our study. The large number of patients included could have distorted the relationship between $p$ values and the clinical relevance of the differences found.

Finally, due to the nature of our cohort (ie, not an inception cohort) criterion of proportionality regarding to the risk of death, was not fulfilled. In fact, we observed that the effect of all systemic rheumatic diseases examined on all-cause mortality increased over time, in parallel to the observation period/disease duration. This can be attributed to tighter control of disease closer to diagnosis and accumulation of comorbid conditions related or not to inflammation.

In conclusion, based on current data, all-cause mortality of patients who are treated for RA is almost comparable to the general population, whereas, for patients with spondyloarthropathies, mortality rates are in fact lower for the first 3 years of observation becoming similar to the general population thereafter. Availability of effective therapeutic options, treat-to-target strategies and perhaps better control of cardiovascular comorbidities over the last years might explain our results which pertain to calendar years 2015-2019. Similar strategies could be adopted for the other systemic rheumatic diseases as well. As shown in other studies as well, disease duration seems to negatively affect mortality in all systemic rheumatic diseases, leading to slightly increased mortality risk for RA and to abolishment of reduced mortality for SpA, 3 years after disease diagnosis. Male gender and younger age in SLE and SSc are adverse prognostic factors, highlighting that these patients need closer follow-up and more effective treatments.

Contributors V-KB contributed in study design, statistical analysis, curation of data and drafting the manuscript, GEF contributed in study design and drafting the manuscript, KM, AT and PM contributed in data curation and analysis, GK and GV contributed in statistical analysis, DP contributed in study design and statistical analysis, MGT contributed in study design and critically revised the manuscript, PPS conceived the original idea, supervised the project and contributed in study design, data analysis, writing and reviewing the manuscript. PPS acting as guarantor has full responsibility for the finished work and the conduct of the study, had access to the data, and controlled the decision to publish.

Funding The authors have not declared a specific grant for this research from any funding agency in the public, commercial or not-for-profit sectors.

Competing interests None declared.

Patient consent for publication Not applicable.

Ethics approval Permission for use of anonymised data deposited in the e-Government Center for Social Security Services (IDIKA) database was obtained from the Greek Ministry of Health following the approval of our formal request, according to the European legislation for General Data Protection Regulation, (27 April 2016) and the national laws (4600/2019, 4624/2019, 3892/10, 3418/2005).

Provenance and peer review Not commissioned; externally peer reviewed.

Data availability statement Data may be obtained from a third party and are not publicly available. Data may be obtained on reasonable request form a third party. Use of data for this study was licensed from the Data Protection Officer of the Greek Ministry of Health, following submission of a formal request and approval of the study protocol.

Open access This is an open access article distributed in accordance with the Creative Commons Attribution Non Commercial (CC BY-NC 4.0) license, which permits others to distribute, remix, adapt, build upon this work non-commercially, and license their derivative works on different terms, provided the original work is properly cited, appropriate credit is given, any changes made indicated, and the use is non-commercial. See: http://creativecommons.org/licenses/by-nc/4.0/. 
ORCID iDs

Vasiliki-Kalliopi Bournia http://orcid.org/0000-0002-2162-1362

George E Fragoulis http://orcid.org/0000-0003-4932-7023

Maria G Tektonidou http://orcid.org/0000-0003-2238-0975

\section{REFERENCES}

1 Toledano E, Candelas G, Rosales Z, et al. A meta-analysis of mortality in rheumatic diseases. Reumatol Clin 2012;8:334-41.

2 Ziade N, El Khoury B, Zoghbi M, et al. Prevalence and pattern of comorbidities in chronic rheumatic and musculoskeletal diseases: the COMORD study. Sci Rep 2020;10:7683.

3 Colaco K, Widdifield J, Luo J, et al. Trends in mortality and causespecific mortality among patients with psoriasis and psoriatic arthritis in Ontario, Canada. J Am Acad Dermatol 2021;84:1302-9.

4 Fragoulis GE, Chatziodionysiou K, Nikiphorou E, et al. Damage Accrual in rheumatoid arthritis: evaluating the joint and beyond. Arthritis Rheumatol 2020;72:1967-70.

5 Ogdie A, Haynes K, Troxel AB, et al. Risk of mortality in patients with psoriatic arthritis, rheumatoid arthritis and psoriasis: a longitudinal cohort study. Ann Rheum Dis 2014;73:149-53.

6 Tselios K, Gladman DD, Sheane BJ, et al. All-Cause, cause-specific and age-specific standardised mortality ratios of patients with systemic lupus erythematosus in Ontario, Canada over 43 years (1971-2013). Ann Rheum Dis 2019;78:802-6.

7 Ogdie A, Maliha S, Shin D, et al. Cause-Specific mortality in patients with psoriatic arthritis and rheumatoid arthritis. Rheumatology 2017;56:907-11.

8 Yen EY, Singh DR, Singh RR. Trends in systemic sclerosis mortality over Forty-Eight years, 1968-2015: a US Population-Based study. Arthritis Care Res 2021;73:1502-10.

9 Yen EY, Shaheen M, Woo JMP, et al. 46-Year trends in systemic lupus erythematosus mortality in the United States, 1968 to 2013: a nationwide population-based study. Ann Intern Med 2017;167:777-85.

10 Smolen JS, Schöls M, Braun J, et al. Treating axial spondyloarthritis and peripheral spondyloarthritis, especially psoriatic arthritis, to target: 2017 update of recommendations by an international Task force. Ann Rheum Dis 2018;77:3-17.

11 Thomas K, Lazarini A, Kaltsonoudis E, et al. Treatment patterns and achievement of the treat-to-target goals in a real-life rheumatoid arthritis patient cohort: data from 1317 patients. Ther Adv Musculoskelet Dis 2020;12:1759720X20937132.

12 Dadoun S, Zeboulon-Ktorza N, Combescure C, et al. Mortality in rheumatoid arthritis over the last fifty years: systematic review and meta-analysis. Joint Bone Spine 2013;80:29-33.

13 Lacaille D, Avina-Zubieta JA, Sayre EC, et al. Improvement in 5 -year mortality in incident rheumatoid arthritis compared with the general population-closing the mortality gap. Ann Rheum Dis 2017;76:1057-63.

14 Løgstrup BB, Ellingsen T, Pedersen AB, et al. Cardiovascular risk and mortality in rheumatoid arthritis compared with diabetes mellitus and the general population. Rheumatology 2021;60:1400-9.
15 Zhang Y, Lu N, Peloquin C, et al. Improved survival in rheumatoid arthritis: a general population-based cohort study. Ann Rheum Dis 2017;76:408-13.

16 Elhai M, Meune C, Avouac J, et al. Trends in mortality in patients with systemic sclerosis over 40 years: a systematic review and meta-analysis of cohort studies. Rheumatology 2012;51:1017-26.

17 Pokeerbux MR, Giovannelli J, Dauchet L, et al. Survival and prognosis factors in systemic sclerosis: data of a French multicenter cohort, systematic review, and meta-analysis of the literature. Arthritis Res Ther 2019;21:86.

18 Hao Y, Hudson M, Baron M, et al. Early mortality in a multinational systemic sclerosis inception cohort. Arthritis Rheumatol 2017;69:1067-77.

19 Houge IS, Hoff M, Thomas R, et al. Mortality is increased in patients with rheumatoid arthritis or diabetes compared to the general population - the Nord-Trøndelag Health Study. Sci Rep 2020;10:3593.

20 Abhishek A, Nakafero G, Kuo C-F, et al. Rheumatoid arthritis and excess mortality: down but not out. A primary care cohort study using data from clinical practice research Datalink. Rheumatology 2018;57:977-81.

21 Widdifield J, Bernatsky S, Paterson JM, et al. Trends in excess mortality among patients with rheumatoid arthritis in Ontario, Canada. Arthritis Care Res 2015;67:1047-53.

22 Provan SA, Lillegraven S, Sexton J, et al. Trends in all-cause and cardiovascular mortality in patients with incident rheumatoid arthritis: a 20-year follow-up matched case-cohort study. Rheumatology 2020;59:505-12.

23 Poppelaars PBM, van Tuyl LHD, Boers M. Normal mortality of the cobra early rheumatoid arthritis trial cohort after 23 years of followup. Ann Rheum Dis 2019;78:586-9.

24 Radovits BJ, Fransen J, Al Shamma S, et al. Excess mortality emerges after 10 years in an inception cohort of early rheumatoid arthritis. Arthritis Care Res 2010;62:362-70.

25 Holmqvist M, Ljung L, Askling J. Mortality following new-onset rheumatoid arthritis: has modern rheumatology had an impact? Ann Rheum Dis 2018;77:85-91.

26 Kiadaliri AA, Felson DT, Neogi T, et al. Brief report: rheumatoid arthritis as the underlying cause of death in Thirty-One countries, 1987-2011: trend analysis of World Health organization mortality database. Arthritis Rheumatol 2017;69:1560-5.

27 Prati C, Claudepierre P, Pham T, et al. Mortality in spondylarthritis. Joint Bone Spine 2011;78:466-70.

28 Prati C, Puyraveau M, Guillot X, et al. Deaths associated with ankylosing spondylitis in France from 1969 to 2009. J Rheumatol 2017;44:594-8.

29 Ali Y, Tom BDM, Schentag CT, et al. Improved survival in psoriatic arthritis with calendar time. Arthritis Rheum 2007;56:2708-14.

30 Elalouf O, Muntyanu A, Polachek A, et al. Mortality in psoriatic arthritis: risk, causes of death, predictors for death. Semin Arthritis Rheum 2020;50:571-5.

31 Bower H, Frisell T, Di Giuseppe D, et al. Impact of the COVID-19 pandemic on morbidity and mortality in patients with inflammatory joint diseases and in the general population: a nationwide Swedish cohort study. Ann Rheum Dis 2021. doi:10.1136/ annrheumdis-2021-219845. [Epub ahead of print: 23 Feb 2021]. 